\title{
Estimating food resource availability in arid environments with Sentinel 2 satellite imagery
}

\author{
Caterina Funghi $^{\text {Corresp., } 1,2}$, Renè H.J. Heim ${ }^{2,3}$, Wiebke Schuett ${ }^{1,4,5}$, Simon C. Griffith ${ }^{2,5}$, Jens Oldeland ${ }^{3}$ \\ 1 Institute of Zoology, Universität Hamburg, Hamburg, Germany \\ 2 Department of Biological Sciences, Macquarie University, Sydney, New South Wales, Australia \\ 3 Institute for Plant Science and Microbiology, Universität Hamburg, Hamburg, Germany \\ 4 School of Life Sciences, University of Sussex, Falmer, Brighton, United Kingdom \\ 5 Department of Biological, Earth and Environmental Sciences, University of New South Wales, Sydney, New South Wales, Australia \\ Corresponding Author: Caterina Funghi \\ Email address: caterina.funghi@students.mq.edu.au
}

Background In arid environments, plant primary productivity is generally low and highly variable both spatially and temporally.Resources are not-evenly distributed in space and time (e.g.soil nutrients, water), and depend on global (El Niño/ Southern Oscillation) and local climate parameters. The launch of the Sentinel2-satellite, part of the European Copernicus program, has led to the provision of freely available data with a high spatial resolution ( $10 \mathrm{~m}$ per pixel). Here, we aimed to test whether Sentinel2imagery can be used to quantify the spatial variability of a minor tussock grass (Enneapogon spp.) in an Australian arid area and whether we can identify different vegetation cover (e.g.grass from shrubs) along different temporal scenarios.Although short-lasting, the Enneapogon grassland has been identified as a key primary food source to animals in the arid environment.If we are able to identify and monitor the productivity of this species remotely, it will provide an important new tool for examining food resource dynamics and subsequent animal responses to them in arid habitat.

Methods We combined field vegetation surveys and Sentinel2-imagery to test if satellite spectral data can predict the spatial variability of Enneapogon over time, through GLMMs.Additionally, a cluster analysis ('gower' distance, 'complete' method), based on Enneapogon seed-productivity, and total vegetation cover in October2016, identified three clusters: bare ground, grass dominated and shrub dominated.We compared the vegetation indices between these different clusters from October2016 to January 2017.

Results We found that $\mathrm{MSAVI}_{2}$ and NDVI correlated with the proportion of Enneapogon with seeds across the landscape and this relationship changed over time.Both vegetation indices ( $\mathrm{MSAVI}_{2}$ and $\mathrm{NDVI}$ ) were higher in patches with high seed-productivity of Enneapogon than in bare soil, but only in October, a climatically-favorable period during which this dominant grass reached peak seed-productivity.

Discussion $\mathrm{MSAVI}_{2}$ and NDVI provided reliable estimates of the heterogeneity of vegetation type across the landscape only when measured in the Austral spring. This means that grass cover is related to seedproductivity and it is possible to remotely and reliably predict food resource availability in arid habitat, but only in certain conditions. The lack of significant differences between clusters in the summer was likely driven by the short-lasting nature of the vegetation in the study and the sparseness of the grassdominated vegetation, in contrast to the shrub vegetation cluster that was particularly well measured by the NDVI. 
Conclusions Overall, our study highlights the potential for Sentinel2-imagery to estimate and monitor the change in grass seed availability remotely in arid environments. However, heterogeneity in grassland cover is not as reliably measured as other types of vegetation and may only be well detected during periods of peak productivity (e.g.October 2016). 


\section{Estimating food resource availability in arid environments}

\section{2 with Sentinel 2 satellite imagery}

3

4 Caterina Funghi1, ${ }^{1}$, René H.J. Heim², 5, Wiebke Schuett ${ }^{1,3}$, 4, Simon C. Griffith ${ }^{2,}{ }^{4}$, Jens 5 Oldeland $^{5}$

$6{ }^{1}$ Universität Hamburg, Institute of Zoology, Martin-Luther-King Platz 3, 20146 Hamburg,

7 Germany

$8{ }^{2}$ Macquarie University, Department of Biological Sciences, Sydney, NSW 2109, Australia

$9{ }^{3}$ University of Sussex, School of Life Sciences, Falmer, Brighton BN1 9QG, UK

$10{ }^{4}$ University of New South Wales, Department of Biological, Earth and Environmental Sciences,

11 Sydney, NSW 2052, Australia

125 Universität Hamburg, Institute for Plant Science and Microbiology, Ohnhorststr. 18, 22609

13 Hamburg, Germany

Corresponding author: Funghi Caterina, caterina.funghi@students.mq.edu.au, Martin-Luther-

King Platz 3, 20146 Hamburg, Germany 


\section{Abstract}

20 Background In arid environments, plant primary productivity is generally low and highly variable

both spatially and temporally. Resources are not-evenly distributed in space and time (e.g. soil nutrients, water), and depend on global (El Niño/ Southern Oscillation) and local climate parameters. The launch of the Sentinel 2 satellite, part of the European Copernicus program, has led to the provision of freely available data with a high spatial resolution (10 $\mathrm{m}$ per pixel). Here, we aimed to test whether Sentinel 2 imagery can be used to quantify the spatial variability of a minor tussock grass (Enneapogon spp.) in an Australian arid area and whether we can identify different vegetation cover (e.g.: grass from shrubs) along different temporal scenarios. Although short-lasting, the Enneapogon grassland has been identified as a key primary food source to animals in the arid environment. If we are able to identify and monitor the productivity of this important species remotely, it will provide an important new tool for examining food resource dynamics and subsequent animal responses to them in this arid habitat.

Methods We combined field vegetation surveys and Sentinel 2 imagery to test whether satellite spectral data can predict the spatial variability of Enneapogon over time, through Generalised Linear Mixed Models. Additionally, a cluster analysis ('gower' distance and 'complete' method), based on Enneapogon seed-productivity, and total vegetation cover in October 2016, identified three clusters: bare ground, grass dominated and shrub dominated. We compared the vegetation indices between these different clusters from October 2016 to January 2017.

Results We found that $\mathrm{MSAVI}_{2}$ and NDVI correlated with the proportion of Enneapogon with seeds across the landscape and this relationship changed over time. Both vegetation indices $\left(\mathrm{MSAVI}_{2}\right.$ and NDVI) were higher in patches with high seed-productivity of Enneapogon than in 
41 bare soil, but only in October, a climatically-favorable period during which this dominant grass

42 reached peak seed-productivity.

43 Discussion $\mathrm{MSAVI}_{2}$ and NDVI provided reliable estimates of the heterogeneity of vegetation type 44 across the landscape only when measured in the Austral spring. This means that grass cover is 45 related to seed-productivity and it is possible to remotely and reliably predict food resource 46 availability in arid habitat, but only in certain conditions. The lack of significant differences 47 between clusters in the Austral summer was likely driven by the short-lasting nature of the 48 vegetation in the study, and the sparseness of the grass-dominated vegetation in contrast to the shrub vegetation cluster that was particularly well measured by the NDVI index.

50 Conclusions Overall, our study highlights the potential for Sentinel 2 imagery to estimate and 51 monitor the change in grass seed availability remotely in arid environments. However,

52 heterogeneity in grassland cover is not as reliably measured as other types of vegetation and may only be well detected during periods of peak productivity (e.g. October 2016).

54 Keywords: Australian arid environment, food availability, complex habitat, Sentinel 2

\section{Introduction}

57 In Australian arid environments, plant primary productivity is generally low and highly variable both spatially and temporally, as a result of low levels of average rainfall that are aseasonal, and with high variance in the scale and timing of rainfall events (Noy-Meier, 1973; Morton et al.,

60 2011). Even at a very local scale both annual rainfall, and the individual rainfall events can be very variable (Acworth et al., 2016). As well as presenting an ecological challenge for arid adapted organisms (Letnic \& Dickman, 2006; Morton et al., 2011), this pattern of rainfall presents a 
63 significant challenge to research on Australian arid zone ecology. For example, in their analysis of

6444 years of rainfall data collected over 17 rain gauges across around $380 \mathrm{~km}^{2}$ of the Fowlers Gap

65

66

67

Arid Zone Research Station, Acworth et al. (2016) demonstrated that the rainfall measured in one part of the station is often poorly correlated with that measured in other parts. In a number of representative years, some parts of the research station received more than twice as much rainfall as others, despite being less than $20 \mathrm{~km}$ apart (Acworth et al., 2016). Although at a wide scale a large rainfall event tends to have comparable effects across large areas, ecologically, the difference between these levels of rainfall across local patches will be profound. However, studies that explore the response of animals to rain typically use rainfall records that were taken at distance from the studied population (Zann \& Straw, 1984; Zann et al., 1995), and in many cases use interpolated values between two weather stations that may be hundreds of kilometers from the study area (e.g.: Crino et al., 2017; Pavey \& Nano, 2013). To further confound the problem, the primary productivity on the ground is the result of complex interactions between soils, the water responses of different plant species, climate, seasonality, herbivores' foraging activity, and the total amount and speed at which the rain falls (Reynolds et al., 2004; Morton et al., 2011; Nano \& Pavey, 2013). For example, rainfall events that are timed with the optimal growth phenology of certain species, can elicit a large response on those, but not others. This will promote great landscape heterogeneity at a small spatial scale, and complicate the link between rainfall and netproductivity of components of the arid zone community (Watson, Westoby \& Holm, 1997; Fernández, 2007), in turn making it difficult to draw generalizations about rainfall pulses and arid productivity (Reynolds et al., 2004).

To improve our understanding of animal responses to rainfall, we need to better quantify local primary productivity, rather than using rainfall (or interpolated rainfall) as a proxy. Great 
86 progress has been made in satellite remote sensing, increasing our ability to study the general

87 response of vegetation to rainfall in remote and arid areas. Data archives have become freely

88 available (e.g. Landsat by NASA active since 1972, Wulder et al., 2016) and new satellites have been launched, specifically for land cover change monitoring. For example, the Sentinel 2 satellite, part of the European Copernicus program, provides data with a high spatial resolution (10 m per pixel) that is freely available (running between 2016 and 2028; Skidmore et al., 2015). In temperate climates, where the relationship between abiotic (e.g. rainfall, temperature, soil nutrients) and vegetation productivity is more predictable, satellite remote sensing information has been widely integrated into wildlife research, such as the response to plant phenology of both herbivorous (e.g. mule deer Odocoileus hemionus, Hurley et al., 2014) and non-herbivorous birds and mammals (reviewed in Pettorelli et al., 2011).

Despite this progress, the use of satellite remote sensing to address questions in animal ecology in the arid and semi-arid environment remains particularly challenging. Ground cover is heterogeneous and often sparse with a low vegetation cover and a high soil reflectance (Nagendra, 2001; Okin \& Roberts, 2004; Ren, Zhou \& Zhang, 2018). However, specific vegetation properties (e.g.: density, biomass productivity) can be summarized by calculating spectral vegetation indices, usually combinations of two or more wavelengths/bands (reviewed in: Kalaitzidis et al., 2010; Xue and $\mathrm{Su}, 2017)$. Many studies of arid areas have tried the most suitable vegetation indices to reliably estimate the variation in vegetation type and density across the landscape (e.g.: Asia, Kang et al., 2018; Africa, Mapfumo et al., 2016; North and Central America, Théau and Weber, 2010; Australia, Chen et al., 2014), finding that a vegetation index based on higher spatial resolution imagery better represent the actual situation on the ground. However, the use of a single vegetation index to summarize such a complex environment is not a reliable tool (Okin \& Roberts, 2004; 
109 Hamada et al., 2019). Given the sparseness and patchiness of vegetation in the landscape, modern 110 and highly resolved Sentinel 2 imagery (compared to previously used Landsat data at $30 \mathrm{~m}$ 111 resolution) may provide a better tool to predict the productivity of different components of the 112 vegetation, such as grasses. Data with a higher resolution will be more suitable in reflecting the 113 heterogeneity of complex vegetation patterns on the ground, and the signal may be less 114 overwhelmed by more dominant, and perennial shrub species such as Acacia spp. This is important 115 because whilst there may be a general 'greening response' to rainfall, it does not necessarily 116 provide evidence of a resource base for a particular guild of animals. For example, the nutritional 117 requirements of the seed-eating zebra finch (Taeniopygia guttata) have been well characterized, with the seeds of dominant grass species such as Enneapogon spp. making up a considerable 119 portion of their diet $(>80 \%)$ in the Austral spring, triggering reproduction (Morton \& Davies, 1983). However, these grasses often occur amongst patches of chenopod shrubs that provide little or no nutrition to this granivorous species, and may have a greening response to rainfall, perhaps at other times of the year, that does not support growth of Enneapogon spp. Therefore, remotely measured indices derived from a suboptimal spatial resolution for the landscape in study, such as the Landsat-derived Normalised Difference Vegetation Index (NDVI, Tucker, 1979), may reveal a strong response that may be driven by variation in chenopod shrubs, and not reflect a response by other components of the vegetation, such as seed grasses, that are of relevance to granivorous 127 species.

To date, most of the work on Australian extended arid grassland areas have attempted to relate satellite remote sensing information to areas dominated by perennial, sclerophyllous and tall grass species (Chen, Scientific \& Gillieson, 2014). While Australian arid primary productivity is generally considered to be based on perennial, summer grasses like Triodia and Plechrachene spp. 
132 (Dickman et al., 2014); during the Austral spring, when the climate is most amenable for

133 reproduction in many groups of animals such as birds (Duursma, Gallagher \& Griffith, 2017), and

134 while the summer grasses are still quiescent, the Enneapogon spp. are the most dominant grasses

135 representing the main food source for a variety of animals (Buckley, 1982; Hoffmann, 2010). The

136 Enneapogon genus is composed by minor tussocks (around $30 \mathrm{~cm}$ height), with 15 short-perennial

137 species present in Australia (i.e.: biannual, Foulkes et al., 2014; Kakudidi et al., 1988). The seed-

138 productivity of Enneapogon grassland is commonly represented by a matrix of different

139 Enneapogon species (hereafter generally called 'Enneapogon') that peaks in favourable springs,

140 in response to winter rains, and before the perennieal summer grasses start to grow.

By correlating the actual vegetation cover with remotely acquired spectral vegetation

142 indices, it will be possible to determine the extent to which a remotely acquired signal represents

143 vegetative growth in a particular area, and reflects different components of the plant community

144 (Chen, Scientific \& Gillieson, 2014). The seed-productivity and ground cover of Enneapogon in

145 the arid landscape is not reliable and depends on the complex interactions with rainfall and other

146 abiotic factors (e.g. temperature, soil nutrients). If the higher spatial resolution of Sentinel 2

147 imagery is able to capture the seed-productivity of Enneapogon in the arid landscape, this will

148 provide new opportunities to understand the ecological response of seed-eating animals that

149 primarily use these grasses over time and space. Here we combined field vegetation surveys and

150 Sentinel 2 images that temporally matched the field sampling to directly test: (1) whether satellite

151 remote sensing data (i.e. spectral vegetation indices that measure vegetation structure and cover)

152 can be used to predict the spatial variability of Enneapogon seed-productivity in a heterogeneous

153 and arid environment and (2) whether the spectral vegetation indices might be used to identify

154 different vegetation cover (e.g.: grass from shrubs) along different temporal scenarios. This would 
155 allow studies to remotely and reliably monitor the actual food availability dynamics in arid habitat,

156 providing new insight to the study of arid zone animal population dynamics. The study objectives

157 were addressed through two main field approaches. The first approach aimed to directly quantify

158 Enneapogon seed-productivity across the landscape over an area of approximately $12.5 \mathrm{~km}^{2}$,

159 during October, December 2016 and January 2017. We tested the reliability of soil-adjusted and

160 non-adjusted vegetation indices calculated from Sentinel 2 images with $10 \mathrm{~m}$ spatial resolution, to

161 predict the spatial variability of Enneapogon seed-productivity across four months. In other words,

162 we tested whether the satellite-derived indices can be used to predict times with low grass cover,

163 and those times when grass cover and productivity are at their peak. The duration of the study from

164 October 2016 to January 2017 permitted the capture of vegetation changes associated with the

165 changing season and conditions in this arid environment, from an exceptionally productive Austral

166 Spring in October (Fig. S1) to a dry Austral Summer in December-January 2017. We expected a

167 link between Sentinel 2-derived vegetation indices and Enneapogon grassland at least in October,

168 when the dominant grass was at its peak of seed productivity and ground cover. The second

169 approach aimed to characterize the general vegetation composition of the landscape in the field, to

170 group areas dominated by different vegetation (i.e. shrub dominated, or Enneapogon dominated)

171 through a cluster analysis, and to test the reliability of the indices over four months between areas

172 with different vegetation types. In this way, we quantified the spatial heterogeneity of the

173 landscape and tested whether it will be possible, in the future, to assess the food productivity (i.e.

174 Enneapogon seeds at its productivity peak) remotely. Determining the extent to which Sentinel's

175 higher spatial resolution is capable of reliably representing vegetation heterogeneity in arid areas,

176 across the landscape and over time, particularly for different parts of the vegetation community

177 such as grasses, will guide the potential application of this imagery to become an important tool in 
178 attempts to understand the relationship between primary productivity and the ecological responses

179 of animals in such an ecologically unpredictable environment.

\section{Materials and Methods}

\section{Study area and field surveys}

183 The study was focused on an area - Gap Hills - located in the north of the Fowlers Gap Arid Zone

Research Station $\left(31^{\circ} 05^{\prime} 13.1^{\prime \prime} \mathrm{S}, 141^{\circ} 42^{\prime} 17.4^{\prime \prime} \mathrm{E}\right)$, New South Wales, Australia. Fowlers Gap is one

of the few long-term study sites in the Australian arid zone, where the population dynamics of several animal species have been monitored over long periods of time. Therefore, it is a strategic location to test whether food resource availability (i.e. primary productivity) can be reliably assessed remotely, to start linking animal dynamics and food availability in arid environments in the future. In October 2016, 36 quadrats of $10 \times 10 \mathrm{~m}$ were established in an area within $2 \mathrm{~km}$ of an artificial water dam (Fig. 1a), an important resource for the animals in the study area. In each quadrat, we identified all plants at the lowest taxonomical level possible (i.e. species or genus). For every identified plant, we estimated the percentage of vegetation cover and noted the dominant genus of the overstorey, the understorey and for grasses. The total vegetation cover was estimated by considering the highest vegetation cover between the overstorey, understorey and grasses.

To quantify the variability of seed-productivity in the Enneapogon spp. across the every quadrat, during three weeks, between the $28^{\text {th }}$ October and the $16^{\text {th }}$ November 2016 . The average of the data gathered over these three weeks corresponded to the October values used in the statistical analysis. For every meter in each of our transects, we noted the name of the grass 
$20110 \mathrm{~cm}$. Additionally, we randomly collected 50 spikelets with seeds of the most dominant grass

202 genus, Enneapogon, from different individuals around the transect (and quadrat) area. In this way,

203 the seed-productivity was calculated by estimating the proportion of Enneapogon spp. with seeds

204 multiplying it with the average dry weight of one spikelet across the three weeks of sampling

205 ( $\mathrm{g}^{*}$ seed/transect, analytical balance: Sartorius BP211D, Wood Dale, Illinois, 0.01mg). In

206 December 2016 and January 2017, we returned once to every location and performed the transect

207 surveys. We estimated the seed-productivity of each transect location, that overlapped with each

208 quadrat location, per each month. We multiplied the proportion of Enneapogon spp. with seeds by

209 the average dry weight of one spikelet (from October-November spikelet collection).

In order to characterize the general vegetation composition of the landscape and identify areas dominated by different vegetation, we used the field-based data from our quadrats of October 2016 to estimate the presence of vegetation co-occurrence. We identified the most dominant 19 plant genera and built a matrix of the contribution of each to the plant cover across the plots. The cover-plot matrix was combined with the estimation of total cover and Enneapogon seed215 productivity ('gower' distance in 'vegdist' for 'vegan' package and 'complete' method in 'NbClust' for 'NbClust' package in R; R Core Team 2014, Charrad et al., 2014; Oksanen et al., 2017) to run a global non-metric multidimensional scaling analysis (NMDS) to identify different vegetation clusters (Fig. 1b): the Enneapogon-based ('grass') and the shrubs-based ('shrub', Table S1). Furthermore, an indicator species analysis was run to statistically assess the strength of species-clusters associations. This analysis is based on permutation tests and an indicator value index that is the product between the relative frequency of occurrence for each species in each

222 cluster and the relative abundance (cover) of each species in each cluster ('IndVal.g' methods in 223 the 'multipatt' function in 'indicspeces' package, De Cáceres \& Legendre, 2009). The quality of 
224 the overall ecological conditions is also determined by the amount of bare ground, and we

225 manually built a third cluster selecting the 'bare ground' quadrats, defined by total vegetation cover

226 estimation being less than $10 \%$ (Fig. 1). Later we used the same clusters to test the suitability of

227 the satellite-derived vegetation indices to discriminate between a subset of quadrat locations

228 identified inside these clusters.

229

230 Satellite imagery

231 In order to best match the period of field data collection (Enneapogon seeds productivity sampled

232 between $28^{\text {th }}$ October and $16^{\text {th }}$ November 2016) and the satellite-derived indices, we chose the 233 imagery available from Sentinel 2 (Copernicus Earth Observation Program, Thales Alenia Space,

234 ESA, 2015), with cloud free conditions for the study period, which was $29^{\text {th }}$ October 2016. To

235 analyze the temporal changes, from the Austral spring 'boom' (October-November) to the dry arid

236 summer (December-February), the images selected were taken from the $18^{\text {th }}$ December 2016 and

237 the $27^{\text {th }}$ January 2017 (both $0 \%$ cloud cover). We were unable to use images from November,

238 because it was cloud affected. Images were projected into the WGS 84/UTM zone 54S coordinates

239 reference system. For removing atmospheric effects, we applied the dark object subtraction

240 procedure (Chavez, 1988) using the Semi-Automatic classification tool (Congedo, 2016) which is

241 available as a plugin for QGIS (v 2.18.17, QGIS Developer Team 2019). For the high spatial

242 resolution satellite images from all periods (October, December 2016 and January 2017), we

243 calculated the two vegetation indices previously shown to perform well in arid and semi-arid areas

244 (Chen et al., 2014, Table S2). The Modified-Soil-Adjusted Vegetation Index (MSAVI ${ }_{2}$, (Qi et al.,

245 1994) is adjusted for the reflectance of the exposed soil, whereas the Normalized Difference

246 Vegetation Index (NDVI, Tucker, 1979) is not adjusted. Both of these indices use the near infrared 
247 (NIR, $0.84 \mu \mathrm{m}$, band 8) and red wavelength reflectance (Red, $0.66 \mu \mathrm{m}$, band 4, Table S2). The

248 indices were calculated at native spatial resolution (10 $\mathrm{m}$ for $\left.\mathrm{MSAVI}_{2}, \mathrm{NDVI}\right)$, for each of the 36

249 GPS plots/transects points ( \pm 5 m, GPSMAP ${ }^{\circledR}$ 64s, Garmin, Olathe, USA), projected into WGS

$25084 / \mathrm{UTM}$ zone $54 \mathrm{~S}$ coordinates reference system. Therefore, we obtained the value of $\mathrm{MSAVI}_{2}$ and

251 NDVI for a $10 \times 10 \mathrm{~m}$ (proxies of pixel) square which included the GPS point used as reference

252 for the field-based work.

\section{Statistical analysis}

255 The spectral vegetation indices used are measurements of vegetation structure and cover, therefore,

256 to validate the satellite remote sensing information against field based data across time, we

257 considered the sampled transects that had a value of the Enneapogon seed-productivity larger than

258 zero. Further, in order to balance the sample sizes of transects (larger in October), we additionally

259 subset the transects considering the ones that in October had higher than mean seed-productivity.

260 Therefore, for these analyses the final sample size was 23 transects: three transects were repeated

261 each of the three months in study, ten repeated twice and ten transects had no repeated

262 measurements (i.e.: $\mathrm{n}_{\mathrm{observation}}=39$ ). Our measures of Enneapogon seed-productivity (i.e.: the

263 product of the proportion of Enneapogon with seed and the average dry-weight of one spikelet)

264 had a distribution not suitable to be modeled (neither as proportion nor Gaussian). For the analyses

265 of the spectral vegetation indices validation, we used directly the proportion of Enneapogon with

266 seeds over the total number of spikelets counted for each transect survey, which was highly

267 correlated with the Enneapogon seed-productivity ( $r h o=0.9, \mathrm{P}<0.001, \mathrm{n}=39$ ). Having checked that

268 the subset data met the assumptions for the spatial autocorrelation (Moran's $I$ test) and the linear

269 model assumptions, we built two separate Generalised Linear Mixed Models (GLMM) with 
270 proportional error distribution that is a binomial weighted for the total of the proportion (i.e. total

271 number of spikelets counted for each transect survey). The proportion of Enneapogon with seeds

272 of the subset locations was fitted as the dependent variable. Either $\mathrm{MSAVI}_{2}$ or NDVI of the same

273 quadrat (measured at $10 \mathrm{~m} \times 10 \mathrm{~m}$ pixel as approximation of transect line surveys), the months

274 (October, December and January) and their interaction were fitted as explanatory variables;

275 transect location ID was fitted as random effect. Full models were always reduced by removing

276 the least significant terms in a stepwise process, starting with the interactions as determined by

277 likelihood ratio test between models (Crawley, 2007); until only significant terms remained and

278 terms included in significant interactions. For GLMMs we used the package 'Ime4' (Bates et al.,

279 2014). Furthermore, we estimated a model quality index for each model, the conditional pseudo-

$280 \mathrm{R}^{2}$ (using 'r.squaredGLMM' function in 'MuMIn' package, Barton, 2019) that represents the

281 variance explained by the entire model, including both fixed and random effects.

We tested the performance of the soil-adjusted $\mathrm{MSAVI}_{2}$ and the NDVI in distinguishing

between patches with different vegetation cover over time. We tested a best-case scenario in which

we considered a subset of five quadrats that were most representative of the three different clusters

(i.e.: five of each type, Table 1) to balance the sample size and thereby excluding quadrats with mixed vegetation types that might otherwise confound these estimates. Having checked for significant differences between the quadrats representing each cluster (Table S3), a series of paired Wilcoxon's signed rank tests, separately for each month, was run between the subset of quadrats representing each cluster. Each of the three tests were Bonferroni adjusted for multiple comparison. For comparison tests we used the package 'stats' and all statistical analyses were conducted within the statistical environment of R (R Core Team 2014). 


\section{Results}

294 The spatial autocorrelation value, Moran's I, for the proportion of Enneapogon with seed

$295\left(\mathrm{n}_{\text {IDlocation }}=23\right)$ in study was -0.02 , not significantly different from randomness (i.e.: Moran's $I=0$,

$296 \mathrm{p}=0.8)$. The proportion of Enneapogon with seed was related with both $\mathrm{MSAVI}_{2}($ Table 2, Fig. 2a,

$297 \mathrm{n}_{\text {ID location }}=23, \mathrm{n}_{\text {observation }}=39$ ) and NDVI (Table 2, Fig. 2b, $\mathrm{n}_{\text {ID location }}=23, \mathrm{n}_{\text {observation }}=39$ ) but the

298 relationship changed over time, as the interaction between vegetation index and month was

299 significant for both models (Table S4). In October $\left(\mathrm{n}_{\text {IDlocation }}=21\right) 2016$, the higher the proportion

300 of Enneapogon with seed (correlated with seed productivity), the higher were the vegetation

301 indices. The indices reflected the variability in Enneapogon with seed across the landscape (Table

302 2). In December $2016\left(n_{\text {IDlocation }}=12\right)$ and January $2017\left(\mathrm{n}_{\text {IDlocation }}=6\right)$ the same relationship was

303 negative, although the reduced sample size does not allow general interpretations (Fig. 2). The

304 conditional pseudo- $\mathrm{R}^{2}$ (model quality index) was 0.68 for the model with the $\mathrm{MSAVI}_{2}$ and 0.7 for

305 the one with NDVI.

The three clusters identified differed in their vegetation composition (Fig. 1, Table S1).

307 The bare ground plots $(n=10)$, represented mainly bare soil with a total cover of less than $10 \%$

$308(3.5 \pm 1.5 \%$ mean $\pm \mathrm{SD})$; the grass cluster was composed of plots $(\mathrm{n}=21)$ in which Enneapogon and 309 succulent smaller bushes (e.g.: Scleroleana spp.) were indicator species (Table S1), while only

310 few forbs and Acacias spp. appeared (Table S1). For the shrub plots $(\mathrm{n}=5)$, located in close

311 proximity to the water channel, the indicator species were herbaceous and leafy shrubs vegetation

312 (e.g.: Acacias spp., Medicago spp., Table S1).

With respect to NDVI, there were significant differences between bare ground and shrub vegetation patches, and shrub and grass patches in October, December and in January (Table 3).

315 A significant difference between the NDVI of bare ground and grass patches was only detected in 
316 December (Table 3, Fig. 3d-f), although the test value Z-score was just over the significance 317 threshold.

The equivalent results for the $\mathrm{MSAVI}_{2}$ index revealed significant differences across the three different vegetation cover in October, when the vegetation was at its peak (Table 3, Fig. 3a), but in December and January, during the dry Summer, the difference between bare ground and shrub was significant, whereas the comparisons between other clusters were not significantly different (Table 3, Fig. 3b, c).

\section{Discussion}

325 Using on-ground measures of vegetation structure and Enneapogon seed-productivity we tested the extent to which Sentinel 2 satellite images can be used to indicate habitat quality, and potential food resource availability (i.e. Enneapogon), in the spatially heterogeneous Australian desert and semi-desert. The results suggest it is possible to detect remotely differences in vegetation cover between patches over time, if these patches were previously chosen as dominated by specific vegetation types (e.g.: grass, shrubs, bare ground), although with some limitations. We based the vegetation characterization focusing on a sample period (October 2016), where the whole vegetation in the study area was at the 'boom' phase of the characteristic 'boom and bust' cycle, as a consequence of good winter rainfall (Morton et al., 2011), and confirmed by this period having the highest NDVI value since 2010 (Fig. S1). This allowed us to get a rare estimation of the vegetation cover and the Enneapogon seed-productivity across the landscape during extremely favorable conditions. proportion of Enneapogon with seeds (highly correlated with seed-productivity) across the 
339 landscape, at least in October. Furthermore, the cluster analysis showed that Enneapogon was most

340 likely to be spatially associated with succulent shrubs Scleroleana spp. On the other hand, areas

341 closer to the semi-permanent dam were dominated by Acacia and a few species of forbs. The

342 distribution of vegetation supported previous studies which found the presence of artificially

343 damned water to influence the spatial distribution of vegetation types, perhaps through the effect

344 of heightened grazing (around dams) that favors shrubland over grassland (James, Landsberg \&

345 Morton, 1999). In our field site the water dam is also along a dry-creek system that might further

346 influence the vegetation response found, with the taller and greener vegetation distributed along

347 the ephemeral creek. Actually, dry creeks have been demonstrated to increase the soil water

348 content in the adjacent area, by prolonging the effect of flood after rain events, and triggering a

349 strong vegetation response (Kingsford, Curtin \& Porter, 1999; Morton et al., 2011). Therefore, it

350 is likely that these environmental structures and their associated effects interact to shape the spatial

351 vegetation variation detected by the Sentinel-derived indices, even at local scales.

The other aim of the present study was to validate the relationship between spectral

vegetation indices and vegetation patch cover over time. Plots that equate to the size of a pixel in

the satellite imagery are rarely comprised of pure vegetation cover of a single type of vegetation

in arid habitat. However, to validate the potential of Sentinel 2 imagery to in arid zone ecology, it

is important to discriminate and monitor the cover of different vegetation patch types over time.

Thus, our results related the grass cover with seed-productivity, allowing its monitoring from the

space, knowing that the satellite-derived vegetation indices will detect only the peak of availability across Gap Hills remotely, if one can focus on patches that are known to contain grass, 
362 spectral vegetation indices from these potential areas of grass, the imagery should be able to

363 discriminate effectively between times with low grass cover, and those times when grass cover

364 and productivity is at its peak. The lack of temporal reliability shown in December and January

365 could be due to the short-lasting nature of the vegetation, rather than an actual unreliability of the

366 satellite sensitivity signal. The spectral vegetation indices we used are designed to detect greenness

367 differences (i.e. wavelengths' spectra) emitted from the vegetation (Kalaitzidis, Heinzel \& Zianis,

368 2010; Xue \& Su, 2017). Therefore, they are expected to be influenced by vegetation phenology.

369 Additionally, when we considered the clusters' subset that best characterized the different

370 dominant vegetation kind (or bare soil), we found that only in October the $\mathrm{MSAVI}_{2}$ was able to

371 distinguish between areas with high Enneapogon seed-productivity, bare soil and dense shrub

372 vegetation. However, the difference between the most stable clusters, the shrub and bare ground

373 quadrats, held even when the environmental conditions became more arid (January 2017), despite

374 the reduced power of the analysis at that time due to the reduced sample size of the quadrats'

375 subset. Other satellite remote sensing techniques and indices might be more suitable for detecting

376 specific changes in phenology accounting for changes in water, chlorophyll content and plant litter

377 (e.g.: Berry and Roderick, 2002; Szabó et al., 2016).

We detected a slight difference in performance between the soil-adjusted $\mathrm{MSAVI}_{2}$ and soilunadjusted NDVI along time and across clusters, with the NDVI always detecting the difference between shrub and bare ground and shrub and grass patches, while $\mathrm{MSAVI}_{2}$ mainly distinguished between bare ground and shrub patches. Other studies in arid habitats, found that at low vegetation cover $(<30 \%)$, the unadjusted vegetation index performed better than the adjusted one (e.g.: Ren and Feng 2014). Additionally, a previous study tested the use of several vegetation indices across the whole Fowlers Gap Research Station, using Landsat TM and intensive ground surveys (six 
385

386

387

388

389

390

391

392

393

394

395

396

397

398

399

400

401

402

403

404

405

406

407

transects of $3 \mathrm{~km}$ in 49 sites and $1473 \times 3 \mathrm{~m}$ quadrats, Chen et al., 2014) found that both the MSAVI 2 and NDVI were reliable only in wet conditions. Our results showed that the $\mathrm{MSAVI}_{2}$ and NDVI reliably discriminate between high vegetation cover and bare ground areas over time.

Although the overall size of our study area was much smaller than the area used in other studies in the literature, the analysis of Sentinel's imagery was able to capture the variability across the landscape, when the vegetation was at its peak. Sentinel's higher spatial resolution has been shown to provide higher accuracy in the retrieval of vegetation phenology of an heterogeneous landscape, like a Dutch barrier island, than medium-resolution sensors (e.g. MODIS, Vrieling et al., 2018). Sentinel-derived NDVI seems to better reflect soil moisture condition of areas in extreme drought conditions than lower resolution sensor-based NDVI (West et al., 2018). These results suggest that Sentinel's higher spatial resolution better represents ecologically heterogeneous environments such as the arid ones studied here. This is important, because to understand the responses of particular animals to their environmental fluctuations, we need to focus on the relevant patches of vegetation. Some animals, such as kangaroos and others large herbivorous mammals, may respond to the general greening response detected by the difference between shrub patches and bare ground, because that will reflect the vegetative status and abundance of shrubs - their food. However, for animals that are strictly granivorous i.e. which dependent solely on the productivity of patches of grass that are detectable only when at peak seedproductivity, as demonstrated here, a challenge remains.

An optimal spatial resolution allows a reliable estimation of the structural characterization of plant association (e.g. species identification), maintaining information on vegetation types and abundance, which relates with spectral heterogeneity (Nagendra, 2001). Thus, whilst in homogenous landscapes (e.g. woodland) a lower spatial resolution may be optimal, more complex 
408 and patchy environments (e.g. arid areas) may require a higher spatial resolution to be optimal.

409 For example, to analyze the spatial movement of Topi antelopes (Damaliscus lunatus) and

410 vegetation phenology, MODIS images (250 m spatial resolution) revealed a pattern that AVHRR

411 (5 km spatial resolution) did not detect (Bro-Jørgensen, Brown \& Pettorelli, 2008). Furthermore,

412 understanding animals' individual variation in habitat use is a key step to reveal their variation in

413 breeding phenology and to test the possible evolutionary responses to climate change (Dall et al.,

414 2012; Merilä \& Hendry, 2014). For example, a study over 12 years showed a match between the

415 phenology of oak trees across a woodland, with caterpillar availability, and the individual variation

416 in breeding phenology of a population of great tits (Parus major) and blue tits (Cyanistes

417 caeruleus, Cole et al., 2015). This means that it is possible to evaluate the synchrony between

418 trophic levels at a scale relevant to the individuals in a population, identify the environmental cues

419 used by animals to time their breeding and, consequently, to understand how selection act on these

420 phenological traits (Durant et al., 2007; Cole et al., 2015). In this context, our results, showing the

421 Sentinel-derived indices' discrimination of vegetation types, suggest that $10 \mathrm{~m}$ may be a sufficient

422 resolution to catch some key components of landscape variation in arid environments and,

423 therefore provide a tool for studying animal responses to environmental phenology at a scale

424 relevant to individuals.

\section{Conclusion}

Overall, we showed that the spectral vegetation indices $\mathrm{MSAVI}_{2}$ and NDVI, calculated

427 from the freely available and spatially highly resolved Sentinel 2 satellite images, are able to

428 provide reliable estimates of both spatial and temporal vegetation cover, with some limitations.

429 The temporal reliability seemed to reflect the short-lasting nature of the key plant species present.

430 However, the fine discrimination between vegetation types (i.e. Enneapogon versus shrubs or bare 
431 ground) was accurate only during an ecologically productive period, when this smallest dominant

432 species reached their peak. Less subtle vegetation type discrimination (i.e. bare ground vs shrub

433 vegetation) held over time, despite spatial heterogeneity and prolonged dry conditions that can

434 reduce the 'green-vegetation' signal, especially in an arid environment. Therefore, by previously

435 identifying patches covered by specific vegetation (e.g. performing vegetation surveys when the

436 vegetation in study is at its peak), using Sentinel 2-derived spectral vegetation indices, it might be

437 possible to track their responses to abiotic conditions (e.g. rainfall). In this way, the actual

438 condition of food resource availability (i.e. grass) across a habitat might be estimated at high spatial

439 resolution. Consequently, it would be possible to study how animals respond to this unpredictable

440 environment (including local rainfall variability, Acworth et al., 2016) overcoming the complex

441 relationship between rainfall and vegetation responses, which make generalised predictions quite

442 unreliable (Reynolds et al., 2004). We suggest that the data generated by the Sentinel 2 will provide

443 a reliable estimation of habitat condition (and food availability) over time, with some limitation

444 with respect to some components of the vegetation. Satellite remote sensing of vegetation will

445 enable better long-term studies of animal responses to the vegetative conditions in the arid zone.

\section{Acknowledgements}

448 This work was supported by the 'Deutsche Forschungsgemeinschaft' (SCHU 2927/3-1 to W.S. 449 and S.G.), an ARC Future Fellowship Grant to SCG (FT130101253) and the Joint Degree 450 International Macquarie University Research Excellence Scholarship (iMQRES - 2016204). We 451 thank two Anonymous Reviewers for improving this manuscript with clear and supportive 452 observations; Karen Marais, curator of the Downing Herbarium at Macquarie University, for help 453 and advice with the field survey protocol and for assistance with plant identification; Professor 
454 Mark Westoby for the helpful advice about grass productivity; the Ecology Lab at Macquarie

455 University for all the field work and biomass measuring materials; the director and the manager of

456 Fowlers Gap Research Station for their support; the Dowling family for their kind support in harsh

457 conditions.

458

459

\section{References}

460

461

462

463

464

465

466

467

468

469

470

471

472

473

474

475

476

477

478

479

480

481

482

483

484

485

486

Acworth RI, Rau GC, Cuthbert MO, Jensen E, Leggett K. 2016. Long-term spatio-temporal precipitation variability in arid-zone Australia and implications for groundwater recharge. Hydrogeology Journal 24:905-921. DOI: 10.1007/s10040-015-1358-7.

Barton K. 2019. MuMIn: multi-model inference. :R package version 1.43.6. https://CRAN.Rproject.o.

Bates D, Maechler M, Bolker B, Walker S. 2014. lme4: Linear mixed effects models using Eigen and S4. R package version 1:1-23 http://CRA.

Berry SL, Roderick ML. 2002. Estimating mixtures of leaf functional types using continentalscale satellite and climatic data. Global Ecology \& Biogeography 11:23-39.

Bro-Jørgensen J, Brown ME, Pettorelli N. 2008. Using the satellite-derived normalized difference vegetation index (NDVI) to explain ranging patterns in a lek-breeding antelope: the importance of scale. Oecologia 158:177-182. DOI: 10.1007/s00442-008-1121-z.

Buckley RC. 1982. Ant-plant interactions in Australia. The Hague, Boston. DOI: 10.1007/97894-009-7994-9.

De Cáceres M, Legendre P. 2009. Associations between species and groups of sites: indices and statistical inference. Ecology 90:3566-3574. DOI: 10.1890/08-1823.1.

Charrad M, Ghazzali N, Boiteau V, Niknafs A. 2014. NbClust: an R package for determining the relevant number of clusters in a data set. Journal of Statistical Software 61:1-36.

Chavez PSJ. 1988. An improved dark-object subtraction technique for atmospheric scattering correction of multispectral data. Remote Sensing 24:459-479.

Chen Y, Scientific TC, Gillieson D. 2014. Evaluation of Landsat TM vegetation indices for estimating vegetation cover on semi-arid rangelands - A case study from Australia. Canadian Journal of Remote Sensing 6:1-17. DOI: 10.5589/m09-037.

Cole EF, Long PR, Zelazowski P, Szulkin M, Sheldon BC. 2015. Predicting bird phenology from space: Satellite-derived vegetation green-up signal uncovers spatial variation in phenological synchrony between birds and their environment. Ecology and Evolution 5:5057-5074. DOI: 10.1002/ece3.1745.

Peer) reviewing PDF | (2019:08:40527:3:0:NEW 21 Apr 2020) 
487

488

489

490

491

492

493

494

495

496

497

498

499

500

501

502

503

504

505

506

507

508

509

510

511

512

513

514

515

516

517

518

519

520

521

522

523

524

Congedo L. 2016. Semi-Automatic classification plugin documentation. Technical Report. DOI: 10.13140/RG.2.2.29474.02242/1.

Crawley MJ. 2007. The R Book. West Sussex, England: John Wiley and Sons Ltd, The Atrium, Southern Gate, Chichester.

Crino OL, Buchanan KL, Trompf L, Mainwaring MC, Griffith SC. 2017. Stress reactivity, condition, and foraging behavior in zebra finches: effects on boldness, exploration, and sociality. General and Comparative Endocrinology 244:101-107. DOI: 10.1016/j.ygcen.2016.01.014.

Dall SRX, Bell AM, Bolnick DI, Ratnieks FLW. 2012. An evolutionary ecology of individual differences. Ecology Letters 15:1189-1198. DOI: 10.1111/j.1461-0248.2012.01846.x.

Dickman C, Wardle G, Foulkes J, de Preu N. 2014. Desert complex environments. In: Burns E et al. ed. Biodiversity and environmental change: monitoring, challenge and direction. CSIRO Publishing,.

Durant JM, Hjermann D, Ottersen G, Stenseth NC. 2007. Climate and the match or mismatch between predator requirements and resource availability. Climate Research 33:271-283. DOI: $10.3354 / \mathrm{cr} 033271$.

Duursma DE, Gallagher R V, Griffith SC. 2017. Characterizing opportunistic breeding at a continental scale using all available sources of phenological data: an assessment of 337 species across the Australian continent. The Auk 134:509-519. DOI: 10.1642/AUK-16243.1.

Fernández RJ. 2007. On the frequent lack of response of plants to rainfall events in arid areas. Journal of Arid Environments 68:688-691. DOI: 10.1016/j.jaridenv.2006.07.004.

Foulkes J, Preu N De, Sinclair R, Thurgate N, Sparrow B, White A. 2014. Chenopod and acacia shrublands. In: Emma B et al. ed. Biodiversity and environmental change: monitoring, challenge and direction. CSIRO Publishing,.

Hamada Y, Szoldatits K, Grippo M, Hartmann HM. 2019. Remotely sensed spatial structure as an indicator of internal changes of vegetation communities in desert landscapes. Remote Sensing 11:1-15.

Hoffmann BD. 2010. Using ants for rangeland monitoring: global patterns in the responses of ant communities to grazing. Ecological Indicators 10:1-25.

Hurley MA, Hebblewhite M, Gaillard J-M, Dray S, Taylor KA, Smith WK, Zager P, Bonenfant C. 2014. Functional analysis of Normalized Difference Vegetation Index curves reveals overwinter mule deer survival is driven by both spring and autumn phenology. Philosophical Transactions: Biological Sciences 369:1-15. DOI: 10.1098/rspa.2009.0410.

James CD, Landsberg J, Morton SR. 1999. Provision of watering points in the australianarid zone: a rewiew of effects on biota. Journal of Arid Environmets 41:87-121.

Kakudidi EKZ, Lazarides M, Carnahan JA. 1988. A revision of Enneapogon (Poaceae, Pappophoreae) in Australia. Australian Systematic Botany 1:325-353. 
525

526

527

528

529

530

531

532

533

534

535

536

537

538

539

540

541

542

543

544

545

546

547

548

549

550

551

552

553

554

555

556

557

558

559

560

561

562

563

Kalaitzidis C, Heinzel V, Zianis D. 2010. A review of multispectral vegetation indices for biomass estimation. In: Manakos I, Kalaitzidis C eds. Proceedings of the 29th Symposium of the European Association of Remote Sensing Laboratories, Chania, Greece. IOS Press Ebook, 201-208.

Kang W, Wang T, Liu S. 2018. The Response of vegetation phenology and productivity to drought in semi-arid regions of Northern China. Remote Sensing 10:1-15. DOI: $10.3390 /$ rs 10050727.

Kingsford RT, Curtin AL, Porter J. 1999. Water flows on Cooper Creek in arid Australia determine "boom" and "bust" periods for waterbirds. Biological Conservation 88:231-248.

Letnic M, Dickman CR. 2006. Boom means bust: interactions between the El Niño/ Southern Oscillation (ENSO), rainfall and the processes threatening mammal species in arid Australia. Biodiversity and Conservation 15:3847-3880. DOI: 10.1007/s10531-005-0601-2.

Mapfumo RB, Murwira A, Masocha M, Andriani R. 2016. The relationship between satellitederived indices and species diversity across African savanna ecosystems. International Journal of Applied Earth Observation and Geoinformation 52:306-317. DOI: dx.doi.org/10.1016/j.jag.2016.06.025.

Merilä J, Hendry AP. 2014. Climate change, adaptation, and phenotypic plasticity: the problem and the evidence. Evolutionary Applications 7:1-14. DOI: 10.1111/eva.12137.

Morton SR, Davies PH. 1983. Food of the zebra finch (Poephila guttata), and an examination of granivory in birds of the Australian arid zone. Australian Journal of Ecology 8:235-243. DOI: 10.1111/j.1442-9993.1983.tb01321.x.

Morton SR, Smith DMS, Dickman CR, Dunkerley DL, Friedel MH, Mcallister RRJ, Reid JRW, Roshier DA, Smith MA, Walsh FJ, Wardle GM, Watson IW, Westoby M. 2011. A fresh framework for the ecology of arid Australia. Journal of Arid Environments 75:313-329. DOI: 10.1016/j.jaridenv.2010.11.001.

Nagendra H. 2001. Using remote sensing to assess biodiversity. International Journal of Remote Sensing 22:2377-2400. DOI: 10.1080/01431160117096.

Nano CEM, Pavey CR. 2013. Refining the "pulse-reserve" model for arid central Australia: seasonal rainfall, soil moisture and plant productivity in sand ridge and stony plain habitats of the Simpson Desert. Austral Ecology 38:741-753. DOI: 10.1111/aec.12036.

Noy-Meier I. 1973. Desert Ecosystems: environment and producers. Annual Review of Ecological System:25-52.

Okin GS, Roberts DA. 2004. Remote sensing in arid regions: challenges and opportunities. In: Ustin S ed. The Manual of Remote Sensing. 1-30.

Oksanen J, Blanchet, F. Guillaume Friendly M, Kindt R, Legendre P, McGlinn D, Minchin PR, O’Hara RB, Simpson GL, Solymos P, Henry M, Stevens H, Szoecs, Eduardand Wagner H. 2017. vegan: community ecology package. $R$ package version $2.4-3$.

Pavey CR, Nano CEM. 2013. Changes in richness and abundance of rodents and native predators in response to extreme rainfall in arid Australia. Austral Ecology 38:777-785. DOI:

PeerJ reviewing PDF | (2019:08:40527:3:0:NEW 21 Apr 2020) 
564

565

566

567

568

569

570

571

572

573

574

575

576

577

578

579

580

581

582

583

584

585

586

587

588

589

590

591

592

593

594

595

596

597

598

599

600

601

10.1111/aec. 12062 .

Pettorelli N, Ryan S, Mueller T, Bunnefeld N, Jedrzejewska B, Lima M, Kausrud K. 2011. The Normalized Difference Vegetation Index (NDVI): unforeseen successes in animal ecology. Climate Research 46:15-27. DOI: 10.3354/cr00936.

Qi J, Chehbouni A, Huete AR, Kerr YH, Sorooshian S. 1994. A modified soil adjusted vegetation index. Remote Sensing of Environment 48:119-126.

Ren H, Feng G. 2014. Grass and forage science are soil-adjusted vegetation indices better than soil-unadjusted vegetation indices for above-ground green biomass estimation in arid and semi-arid grasslands? Grass and Forage Science 70:611-619. DOI: 10.1111/gfs.12152.

Ren H, Zhou G, Zhang F. 2018. Using negative soil adjustment factor in soil-adjusted vegetation index (SAVI) for aboveground living biomass estimation in arid grasslands. Remote Sensing of Environment 209:439-445. DOI: 10.1016/j.rse.2018.02.068.

Reynolds JF, Kemp PR, Ogle K, Fernández RJ. 2004. Modifying the “pulse-reserve” paradigm for deserts of North America: precipitation pulses, soil water, and plant responses. Oecologia 141:194-210. DOI: 10.1007/s00442-004-1524-4.

Skidmore AK, Pettorelli N, Coops NC, Geller GN, Hansen M, Lucas R, Mücher CA, O’Connor B, Paganini M, Pereira HM, Schaepman ME, Turner W, Wang T, Wegmann M. 2015. Agree on biodiversity metrics to track from space. Nature 523:403-405.

Szabó S, Gácsi Z, Balázs B. 2016. Specific features of NDVI, NDWI and MNWI as reflected in the land categories. Landscape \& Environment 10:194-202. DOI: 10.21120/LE/10/3-4/13.

Théau J, Weber KT. 2010. Multi-sensor analyses of vegetation indices in a semi-arid environment. GIScience \& Remote Sensing 47:1-16. DOI: 10.2747/1548-1603.47.2.1.

Tucker CJ. 1979. Red and photographic infrared linear combinations for monitoring vegetation. Remote Sensing of Environment 8:127-150.

Vrieling A, Meroni M, Darvishzadeh R, Skidmore AK, Wang T, Zurita-Milla R, Oosterbeek K, O’Connor B, Paganini M. 2018. Vegetation phenology from Sentinel-2 and field cameras for a Dutch barrier island. Remote Sensing of Environment 215:517-529. DOI: 10.1016/j.rse.2018.03.014.

Watson IW, Westoby M, Holm AM. 1997. Continuous and episodic components of demographic change in arid zone shrubs: models of two Eremophila species from Western Australia compared with published data on other species. Journal of Ecology 85:833-846.

West H, Quinn N, Horswell M, White P. 2018. Assessing vegetation response to soil moisture fluctuation under extreme drought using Sentinel-2. Water 10:1-22. DOI: $10.3390 / \mathrm{w} 10070838$.

Wulder MA, White JC, Loveland TR, Woodcock CE, Belward AS, Cohen WB, Fosnight EA, Shaw J, Masek JG, Roy DP. 2016. The global Landsat archive: status, consolidation, and direction. Remote Sensing of Environment 185:271-283. DOI: 10.1016/j.rse.2015.11.032.

Xue J, Su B. 2017. Significant remote sensing vegetation indices: a review of developments and 
602 applications. Journal of Sensors 2017:1-17. DOI: doi.org/10.1155/2017/1353691.

603 Zann R, Morton S, Jones KR, Burley NT. 1995. The Timing of breeding by zebra finches in 604 relation to rainfall in Central Australia. The Emu 95:208-222. DOI: 10.1071/MU9950208.

605 Zann R, Straw B. 1984. Feeding ecology and breeding of zebra finches in farmland in Northern 606 Victoria. Australian Wildlife Research 11:533-552. DOI: 10.1071/WR9840533.

607

608

609 


\section{Figure 1}

Map of the 36 surveys across the Gap Hills and the visual representation of the vegetation composition in the three vegetation clusters.

The spatial distribution of the 36 quadrat10 x10 m surveys on ESRI satellite image, coloured according to the cluster analysis. Map credit: OpenStreetMap, 2016. Licensed under CC BY 3.0 SA. b) Non-metric Multidimensional Scaling (NMDS) visual representation of the vegetation composition (genus of plants identified) and the quadrats surveyed in the three vegetation clusters considered. Grass (blue) and Shrub (green) vegetation categories were identified through a cluster analysis. The Bare ground group (yellow) was manually sorted being the total cover estimation less than $10 \%$ from the grass and shrub clusters. The stress value measures the goodness of fit of the data representation in multivariate space. Graphical distance represents similarity of the green and blue clusters. The location of the vegetation genus represents their co-occurrence.
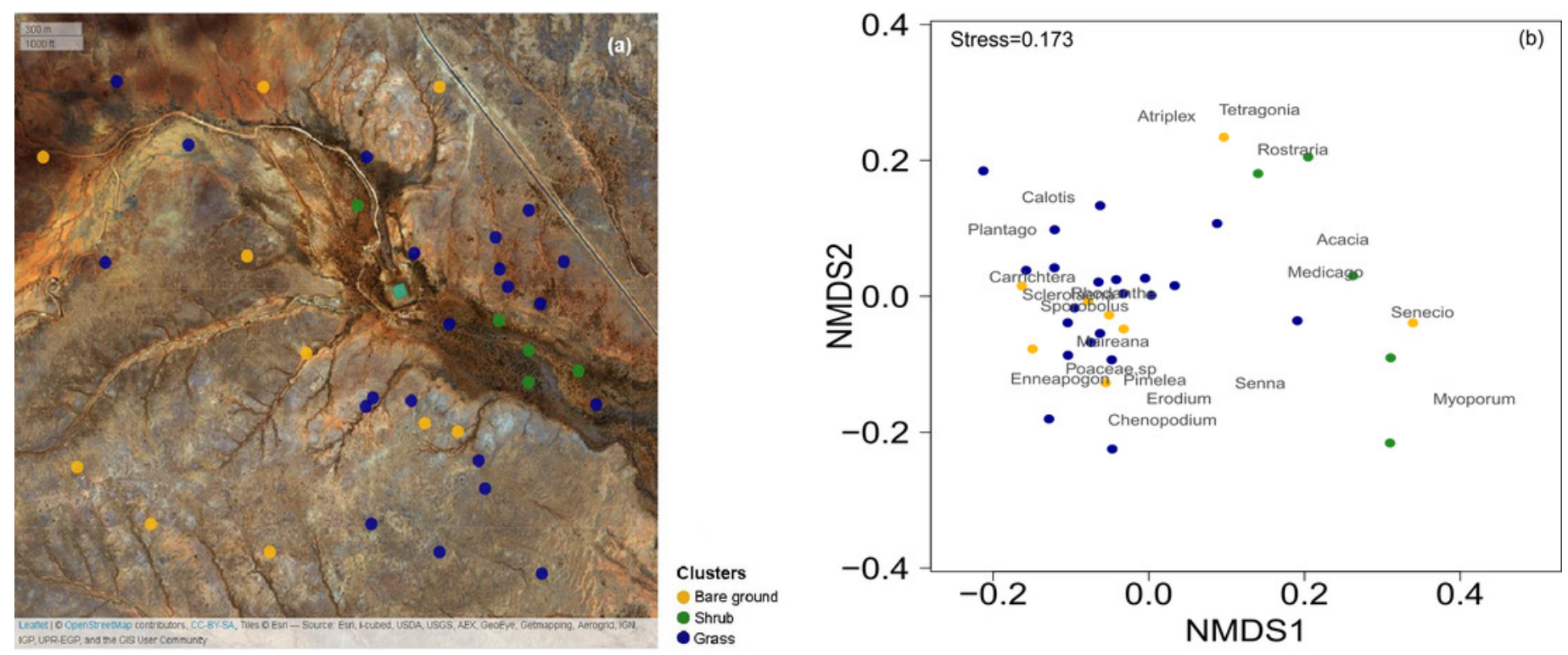
Figure 2

Graphical representation of the relationships modeled with GLMMs.

Binomial-GLMMs of the proportion of Enneapogon with seeds and the spectral indices $\mathrm{MSAVI}_{2}$ (a) and NDVI (b) as predictor. Lines represent the predicted relationships for October 2016 (blue), December 2016 (red) and January 2017 (green).
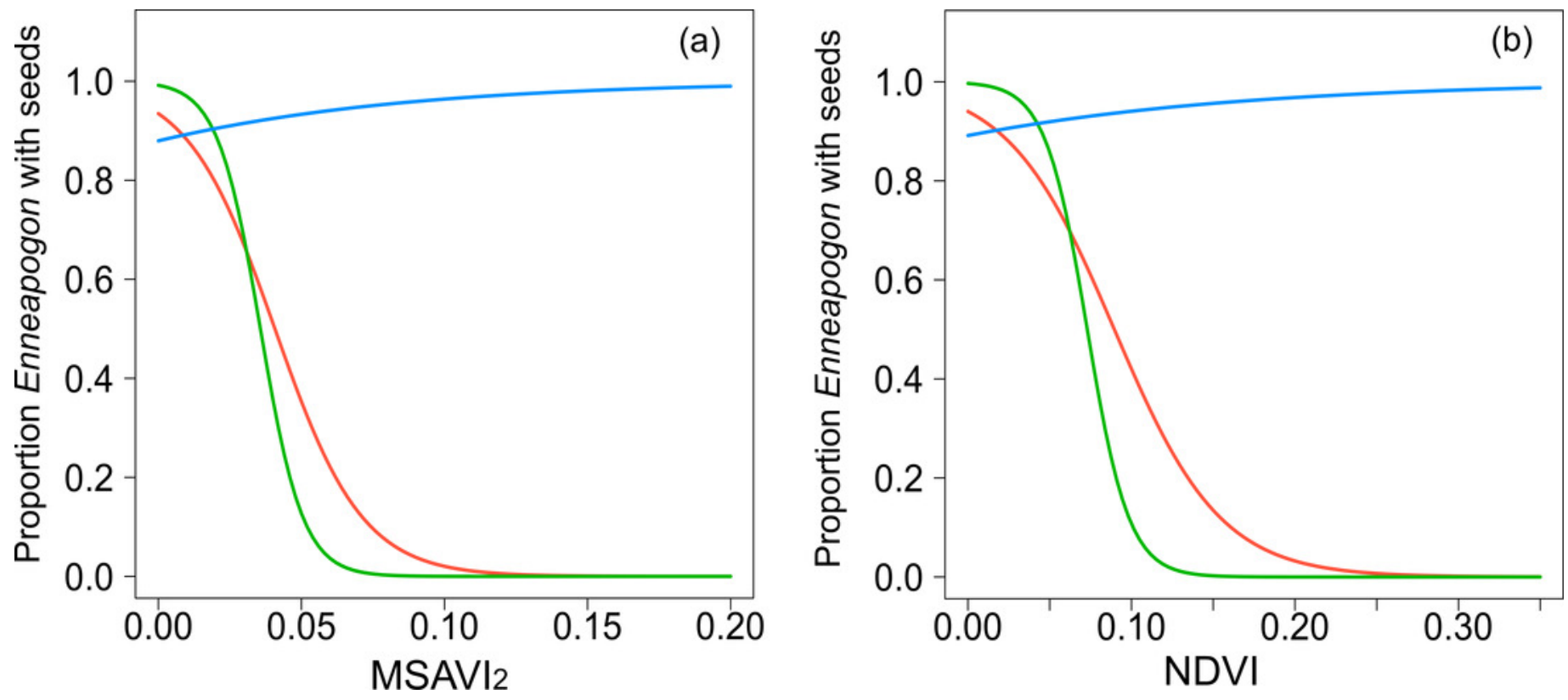


\section{Figure 3}

Comparisons of spectral vegetation indices between clusters at different time.

Bar chart with mean \pm SE to show the comparison of $\mathrm{MSAVI}_{2}(\mathbf{a}-\mathbf{c})$ and NDVI (d-f) extracted from the subset of the three clusters of quadrats with different vegetation type and density. The comparisons were performed for October 2016, December 2016 and January 2017. Significant differences are marked by * and the analyses performed were Wilcoxon's ranked tests and Bonferroni adjusted for multiple comparison.
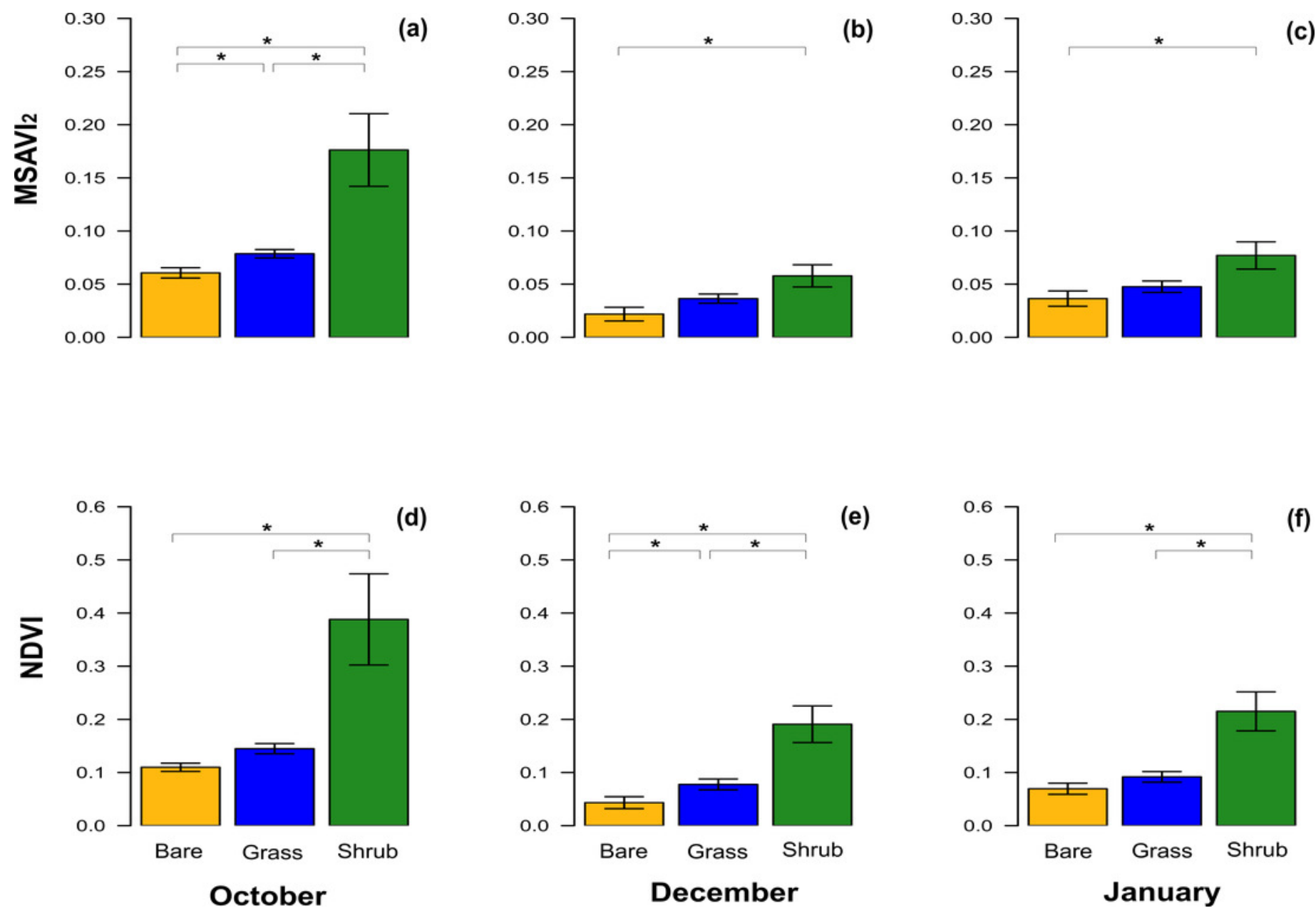


\section{Table $\mathbf{1}$ (on next page)}

Summary of number ( $n$ ) of quadrats, Enneapogon seed-productivity (mean \pm SD) and total vegetation cover (mean \pm SD) of the clusters' subset used for the temporal analysis.

1 Summary of number ( $n$ ) of quadrats, Enneapogon seed-productivity (mean \pm SD) and total vegetation cover (mean $\pm \mathrm{SD}$ ) of the clusters' subset used for the temporal analysis. 
1 Table 1 Summary of number (n) of quadrats, Enneapogon seed-productivity (mean \pm SD) and total

2 vegetation cover (mean $\pm \mathrm{SD}$ ) of the clusters' subset used for the temporal analysis.

\begin{tabular}{lccc}
\hline & Bare & Grass & Shrub \\
\hline $\mathrm{n}$ quadrats & 5 & 5 & 5 \\
$\begin{array}{l}\text { Enneapogon seed-productivity } \\
\text { (proportion* }{ }^{-1} \text { ) }\end{array}$ & $0.03 \pm 0.03$ & $0.17 \pm 0.03$ & $0.001 \pm 0.002$ \\
Total vegetation cover $(\%)$ & $2.8 \pm 1.1$ & $26 \pm 14.4$ & $49.8 \pm 26.8$ \\
\hline
\end{tabular}

3 


\section{Table 2 (on next page)}

Summary of the GLMMs.

Response variables, random terms, and variances (Var) are specified for each model. Values of fixed effects (estimated) and standard errors (S.E.) are logit estimates for the variables in the minimal adequate model. The $X^{2}$ (d.f.) and $P$ values represent the significance of the model, estimated from the comparison between the full model and the reduced one (without the interaction between fixed terms). Statistically significant $P$ values are marked in bold. Each model is based on a total of 39 observations of 23 transect locations 
1 Table 2 Summary of the GLMMs. Response variables, random terms, and variances (Var) are 2 specified for each model. Values of fixed effects (estimated) and standard errors (S.E.) are logit 3 estimates for the variables in the minimal adequate model. The $X^{2}$ (d.f.) and $\mathrm{P}$ values represent the 4 significance of the model, estimated from the comparison between the full model and the reduced 5 one (without the interaction between fixed terms). Statistically significant $\mathrm{P}$ values are marked in 6 bold. Each model is based on a total of 39 observations of 23 transect locations.

\begin{tabular}{|c|c|c|c|c|c|c|c|c|}
\hline & $\begin{array}{c}\text { Response } \\
\text { variable }\end{array}$ & $\begin{array}{c}\text { Random } \\
\text { term }\end{array}$ & Var & Fixed effect* & Estimate & S.E. & $X^{2}$ (d.f.) & $\boldsymbol{P}$ \\
\hline \multirow{7}{*}{$\sum_{\substack{\infty \\
\sum}}^{N}$} & \multirow{7}{*}{$\begin{array}{c}\text { Prop. } \\
\text { Enneapogon } \\
\text { with seeds }\end{array}$} & $\mathrm{ID}_{\text {location }}$ & 3.91 & $\mathrm{MSAVI}_{2}$ : December (Intercept) & 2.66 & 1.04 & & \\
\hline & & & & $\mathrm{MSAVI}_{2}$ & -65.32 & 25.37 & & \\
\hline & & & & January & 2.14 & 1.14 & & \\
\hline & & & & October & -0.67 & 1.58 & & \\
\hline & & & & $\mathrm{MSAVI}_{2}:$ January & -69.15 & 25.45 & & \\
\hline & & & & $\mathrm{MSAVI}_{2}:$ October & 78.28 & 21.89 & & \\
\hline & & & & $\mathrm{MSAVI}_{2}$ :Month & & & $43.65(2)$ & $<0.001$ \\
\hline \multirow{7}{*}{ 之 } & \multirow{7}{*}{$\begin{array}{c}\text { Prop. } \\
\text { Enneapogon } \\
\text { with seeds }\end{array}$} & ID $_{\text {location }}$ & 4.36 & NDVI: December (Intercept) & 2.75 & 1.02 & & \\
\hline & & & & NDVI & -30.76 & 11.22 & & \\
\hline & & & & January & 2.96 & 1.24 & & \\
\hline & & & & October & -0.65 & 1.57 & & \\
\hline & & & & NDVI :January & -47.55 & 14.2 & & \\
\hline & & & & NDVI :October & 37.32 & 11.32 & & \\
\hline & & & & NDVI :Month & & & $41.58(2)$ & $<0.001$ \\
\hline
\end{tabular}

7 


\section{Table 3(on next page)}

Summary of the paired Wilcoxon's signed rank between cluster subsets

Summary of the paired Wilcoxon's signed rank between cluster subsets ( $n=10$ for each comparison). Vegetation index (VI), cluster pairs tested (Pairs), month, coefficient test (Z) and significance $(P)$ are specified for each comparison. Statistically significant values are marked in bold. 
1 Table 3 Summary of the paired Wilcoxon's signed rank between cluster subsets ( $\mathrm{n}=10$ for each 2 comparison). Vegetation index (VI), cluster pairs tested (Pairs), month, coefficient test (Z) and 3 significance $(\mathrm{P})$ are specified for each comparison. Statistically significant values are marked in 4 bold.

\begin{tabular}{llccr}
\hline VI & Pairs & Month & Z & \multicolumn{1}{c}{ P } \\
\hline \multirow{4}{*}{ MSAVI $_{2}$ Bare-Grass } & October & 0.6 & $\mathbf{0 . 0 3}$ \\
& Bare-Shrub & October & 0.7 & $\mathbf{0 . 0 1}$ \\
& Shrub-Grass & October & 0.7 & $\mathbf{0 . 0 1}$ \\
& Bare-Grass & December & 0.4 & 0.1 \\
& Shrub-Grass & December & 0.6 & $\mathbf{0 . 0 2}$ \\
& Bare-Grass & December & 0.4 & 0.2 \\
& Bare-Shrub & January & 0.4 & 0.2 \\
& Shrub-Grass & January & 0.6 & $\mathbf{0 . 0 2}$ \\
& Bare-Grass & October & 0.5 & 0.06 \\
\hline \multirow{4}{*}{ NDVI } & Bare-Shrub & October & 0.7 & $\mathbf{0 . 0 1}$ \\
& Shrub-Grass & October & 0.7 & $\mathbf{0 . 0 1}$ \\
& Bare-Grass & December & 0.6 & $\mathbf{0 . 0 3}$ \\
& Bare-Shrub & December & 0.7 & $\mathbf{0 . 0 1}$ \\
& Shrub-Grass & December & 0.6 & $\mathbf{0 . 0 2}$ \\
& Bare-Grass & January & 0.4 & 0.2 \\
& Bare-Shrub & January & 0.7 & $\mathbf{0 . 0 1}$ \\
& Shrub-Grass & January & 0.7 & $\mathbf{0 . 0 1}$ \\
\hline
\end{tabular}

5

6 